\title{
Escape to Nostril with or without Emission During Swallowing
}

National Cancer Institute

\section{Source}

National Cancer Institute. Escape to Nostril with or without Emission During Swallowing. NCI Thesaurus. Code C127230.

A finding of escape to nostril with or without emission during swallowing. 